\title{
Coagulation Patterns and the Impacts on Traffic- Related Ultrafine Particle Dispersion in Road Tunnels Employing Dynamic Mesh Algorithms
}

\author{
Yu Zhao \\ Dalian University of Technology \\ Wanning Yang \\ Dalian University of Technology \\ Xiaocheng Song ( $\nabla$ sxciscc@163.com ) \\ Dalian University \\ Chaowen Jiang \\ Dalian University of Technology \\ Yao Feng \\ Dalian University of Technology
}

\section{Research Article}

Keywords: Ultrafine particle, Coagulation, Dispersion, Dynamic mesh, Road tunnel

Posted Date: April 6th, 2021

DOI: https://doi.org/10.21203/rs.3.rs-343179/v1

License: (c) (1) This work is licensed under a Creative Commons Attribution 4.0 International License. Read Full License 

University of Technology,

112 Civil and Architectural Engineering College, Dalian University, 10 Xuefu Street, Economic \& Technological 


\section{Abstract}

Following our simulation results in paper (Zhao et al., 2020). In this study we continue to analyze the diffusion mechanism of ultrafine particles and the particle coagulation phenomenon with the size range of 26 287 nm exhausted from the vehicles during the process of passing through a $100 \mathrm{~m}$ long tunnel using the Realizable $k-\varepsilon$ model and the dynamic grid technique. In this paper, a three-dimensional model consisting of a $100 \mathrm{~m}$ highway tunnel and four sideby-side gasoline vehicles $(\mathrm{L} \times \mathrm{W} \times \mathrm{H}=4.5 \mathrm{~m} \times 1.8 \mathrm{~m} \times 1.5 \mathrm{~m})$ were established in the STAR-CCM+ computational fluid dynamics software. The gasoline vehicles travelled simultaneously under the different situations of three driving speeds of $60 \mathrm{~km} \mathrm{~h}^{-1}, 40 \mathrm{~km} \mathrm{~h}^{-1}$ and $20 \mathrm{~km} \mathrm{~h}^{-1}$ during the simulation. Through data analysis and research, it is found that the coagulation process of particles is very complicated, especially at low speeds. When the vehicle speed is $20 \mathrm{~km} \mathrm{~h}^{-1}$, the variation of particle concentration at the vehicle wake near the tailpipe (at the vertical plane located $0.1 \mathrm{~m}$ behind the exhaust pipe) will cause a large error if the coagulation action is not taken into account. The relative error of the average particle concentration at $0.5 \mathrm{~s}$ of the vertical section $0.1 \mathrm{~m}$ away from the exhaust pipe is as high as $193.51 \%$. The relative error in the whole tunnel is only $2.82 \%$, less than $5 \%$, thus the influence of coagulation can be ignored for the whole tunnel. This study clarified the importance of coagulation in different areas and its influence on the diffusion of particulate matter, which is conducive to further analysis of the diffusion characteristics of particulate matter and can appreciably reduce the pollution degree in the tunnel by changing the coagulation efficiency of particulate matter in the future.

Keywords: Ultrafine particle; Coagulation; Dispersion; Dynamic mesh; Road tunnel.

\section{Introduction}

Recently, the number of motor vehicles in China has increased substantially, and ultrafine particles in automobile exhaust have become one of the most important pollution sources in urban areas. Studies have shown that the exposure 
to ultrafine particulate matter affects the incidence of cardiovascular disease and systemic inflammation (Kevin J et al., 2016). Meanwhile, the ventilation systems in closed tunnels at cities in China are closed or semi-closed in the majority throughout the year, which leads to the continuous accumulation of fine and ultrafine particles in urban tunnels. (Svartengren et al., 2000) The harm impact of traffic-related ultrafine particles could not be ignored even during the short period exposure through a road tunnel.

As the accumulation of ultrafine particles occurred more frequently in a closed space compared with other open spaces, ultrafine particles coagulate differently in a closed space like road tunnels than in an open space. Ketzel et al. (2016) simulated the time scale evolution of particle size distribution during vehicle exhaust emissions and dilution, specifically pointed out that in a closed environment, such as a road tunnel, the diffusion of particulate matter is generated by the limited airflow in the tunnel, which is different from the characteristics of an open environment. In a confined environment as a road tunnel the coagulation and deposition play an important role, as it also was concluded by Gidhagen et al. (2003), Sturm et al. (2003) and Park et al. (2004).

The high temperature of vehicle exhaust and high ultrafine particle concentration enhanced the coagulation, especially in the area near the tailpipe. Unfortunately, the literatures related to traffic-related ultrafine particle coagulation are limited. However, the circular jet model is very similar to the jet discharged from exhaust pipe in this paper and has been understood well compared with vehicle exhaust particle coagulation. Zhu et al. (2012) studied the dispersion and coagulation behavior of nanoparticles in turbulent circular jets. In the region of high turbulence intensity, the vortex structure in the mixing layer promoted the coagulation. Meanwhile, Chan et al. (2006) obtained the conclusion that the particle diameter is relatively constant except for the area near the jet and jet interface during the numerical simulation of coagulation and dispersion of nanoparticles in a circular jet. It shows that the coagulation coalescence effect is more obvious in the area near the exhaust pipe, but not in the breathing area and the whole tunnel, 
which is consistent with the conclusion of this paper.

At the same time, the study of coagulation characteristics is of great significance to environmental protection. The bending moment model is adopted to solve the problem of bipolar coagulation in the free molecular region, which can effectively remove pollutants through the coagulation and confluence effect. Yin et al. (2020) proposed a study on the coagulation effect of particles on leaves to purify submicron particles in the air. It can be seen that the research conclusions of this paper can also provide a reference for vehicle exhaust control in the next tunnel.

In fact, ultrafine particles coagulation is indeed a process that cannot be ignored in diffusion and turbulence. The process of collision and viscous hysteresis of small-sized particles into large-sized particles is called coalescence. And the degree of coagulation is usually evaluated by the coagulation rate and half-life time. The study of particle coagulation theory can be traced back to the beginning of the 20th century, Smoluchowski et al. (1984) first proposed a model for the concentration change of polydisperse particles caused by particle coagulation. According to the different mechanisms of particle collision and coagulation, particle coagulation can be divided into Brownian coagulation, gradient coagulation and turbulent coagulation. And particles can be divided into free molecular regime, transition regime, slip flow regime, and continuum regime based on particle size. After the Smoluchowski model, scholars at home and abroad have conducted a lot of theoretical analysis and experimental verification for different coalescence mechanisms and particle partitions. For Brownian coalescence. Fuchs (1964) first proposed that the coalescence collision nucleus in the transition regime can be described by adding a correction factor to the collision nucleus model of the continuum slip flow regime. Wright (1960), Park et al. (1999) and Otto et al. (1999) proposed different correction coefficients to improve Fuchs' correction model. Kim et al. (2006) et al. used a closed environmental chamber under normal pressure to measure the coagulation rate of sodium chloride aerosol particles, and compared it with the Brownian coalescence model of particles to verify the correctness of the Brownian 
coalescence model. For gradient coagulation, Huang et al. (1970) sorted out particle collision nuclei under the action of flow field gradient. This theoretical model was confirmed by the experimental results of Swift and Friedlander (1964) for turbulent coagulation, Saffman and Turner (1956) first proposed the calculation equation of the coalescence collision nucleus caused by turbulent disturbance of water vapor particles in clouds. Okuyama et al. (1977) tested the changes and laws of particle turbulent coagulation in a turbulent environment, and the experimental results well verified the particle turbulent coagulation model proposed by Saffman and Turner 1956. Through reading a large number of literatures, numerous studies focused on the diffusion and movement mechanism of ultrafine particulate matter in closed space, Whereas, few scholars analyze the influence of coagulation confluence on the movement mechanism of particulate matter, and there is no clear conclusion on the influence of coagulation confluence on particulate matter in closed space, especially in road tunnel with high particle concentrations.

Therefore, in this paper, a mathematical model was built by combining three models of particle Brownian coagulation, gradient coagulation and turbulent coagulation, a three dimensional model was established in STAR $\mathrm{CCM}+$ software, and the unsteady turbulence and coagulation characteristic mechanism of ultrafine particles with different diameters emitted from automobile exhaust in the process of urban road tunnel was analyzed in computational fluid dynamics (CFD) numerical simulation. The significance of this article is to reveal the impacts of coagulation on particle dispersion in the tunnel and clarify the range where the ultrafine particle coagulation could not be ignored. The research results can not only be used as basic data for particle unsteady turbulence analysis, epidemiology and health risk assessment, but also provide guidance and basis for subsequent research on ventilation design and pollutant elimination in tunnels. 
Euler - Euler model. Detailed model building formula can refer to equation (2) - (7) in Zhao et al. (2020). Due to the small particle size and variable shape, the movement and diffusion characteristics of automobile emission particles in the tunnel are very complex, and the analysis is difficult or even impossible. In this paper, on the premise of considering the emission particle characteristics of vehicles and the characteristics of the envelope structure and natural ventilation in the tunnel, the following assumptions are proposed to simplify the model for the smooth analysis. fraction in the airflow. Interaction between the air and particles was treated as a one-way coupling, in which the air affected the particles.

b. All particles were spherical, and the particle density was constant. the case of high concentration, particle coagulation has a great influence on the change of particle concentration. Therefore, this paper only considers the influence of coagulation when analyzing the change rate of particle diffusion source phase $S_{c}$. The research in this paper is carried out on the premise of particle diffusion and coagulation coupling rather than isolation.

\section{Particle coagulation model}

The process of collision and viscous hysteresis of small-sized particles into large-sized particles is called

$$
S_{c}=\frac{1}{2} \sum_{m, j=1}^{i-1} \beta_{m j} C_{m} C_{j}-\sum_{a=1}^{n} \beta_{a i} C_{a}
$$


Where $\beta_{m j}, \beta_{a i}$ are the particles coagulation kernel rate, which means the probability of two particles coalescing according to equation (2). 
Where $\lambda$ is the average free path of an air molecule $(\mathrm{m})$, and $d_{P}$ is the particle diameter $(\mathrm{m})$.

$$
\beta_{B}^{t r}=\beta_{B}^{c o} V_{f}
$$

$$
\begin{gathered}
V_{f}=\frac{1+B_{1} K n_{d}}{1+B_{2} K n_{d}+B_{3} K n_{d}{ }^{2}} \\
K n_{d}=\frac{1}{2} \frac{\beta_{B}^{c o}}{\beta_{B}^{f m}}
\end{gathered}
$$



number.

Due to the influence of Brownian diffusion and the streamline shape of the air flow field near the particle wall, the particle gradient coagulation model is quite complicated. This paper ignores the influence of the above two factors on particle gradient coagulation, and uses the gradient coagulation theory given by Huang et al. to study the gradient coagulation changes. The calculation of gradient coagulation nucleus $\beta_{G}$ is detailed in equation (8).

$$
\beta_{G}=\frac{4}{3} \Gamma\left(r_{p i}+r_{p j}\right)^{D_{f}}
$$

Where $\Gamma$ is the velocity gradient at a point in the flow field $\left(1 \mathrm{~s}^{-1}\right), r_{p i}, r_{p j}$ are the radius of particles in the $i$ and $j$ section (m).

\section{Particle turbulence coagulation model}

There are two main reasons for the coagulation of particles in the turbulent flow field: one is the coagulation particles; the other is Coalescence caused by the relative movement between particles of different sizes caused by the turbulent field. Because the mechanism of turbulence is very complicated, the theory of turbulence is not very mature at this stage, and the theory of particle coagulation caused by turbulence is not perfect. Therefore, action of the above two mechanisms to cause turbulent coalescence to analyze the turbulent coalescence of particles 
from gasoline vehicles under the condition of natural tunnel ventilation. The turbulent coagulation nucleus $\beta_{T}$ can be calculated according to equation (9).

$$
\begin{aligned}
& \beta_{T}=2(2 \pi)^{1 / 2}\left(r_{p i}+r_{p j}\right)^{2}\left[\left(1-\frac{\rho_{a}}{\rho_{p}}\right)^{2}\left(\frac{2 r_{p i}{ }^{2} \rho_{p}}{9 \mu}-\frac{2 r_{p j}{ }^{2} \rho_{p}}{9 \mu}\right)^{2} \times 1.3 v^{-1 / 2} \varepsilon^{3 / 2}\right. \\
& \left.+\frac{1}{3}\left(1-\frac{\rho_{a}}{\rho_{p}}\right)^{2}\left(\frac{2 r_{p i}{ }^{2} \rho_{p}}{9 \mu}-\frac{2 r_{p j}{ }^{2} \rho_{p}}{9 \mu}\right)^{2} g^{2}+\frac{1}{9}\left(r_{p i}+r_{p j}\right)^{2} \frac{\varepsilon}{v}\right]^{1 / 2}
\end{aligned}
$$

\section{Important factors affecting the particle coagulation dynamics}

In addition to the three main influencing factors mentioned above, many factors such as van der Waals force and viscous force, various external forces (such as electromagnetic force, etc.), and temperature gradients all have an impact on the change of particle coalescence. Under the natural ventilation of the tunnel, an electromagnetic force of an external force and temperature gradients are not large, and the limited impact on the change in particle coagulation. For nano-sized particles, the influence of van der Waals force and viscous force is relatively large and cannot be ignored in the research process. Van der Waals force is caused by the mutual attraction of wave dipoles in particles, which increases the probability of particle collision and coagulation. The effect of viscous force on particle coagulation is the opposite of van der Waals force, which reduces the probability of particle collision and coagulation. In this paper, the theory proposed by Alam (1987) under the condition of considering the combined effect of van der Waals force and viscous force is used to revise the coagulation of particles. When considering the three factors of Brownian diffusion, flow field gradient and turbulence, and considering the influence of van der Waals force and viscous force on particle coagulation, particle coagulation nucleus $\beta$ can be calculated according to equation (10).

$$
\beta=\left(\beta_{B}+\beta_{G}+\beta_{T}\right) V_{c}
$$




$$
V_{c}^{t r}=\frac{V_{c}^{c o}}{1+\frac{V_{c}^{c o}}{V_{c}^{f m}} \frac{4 D^{\infty}}{\left(r_{p i}+r_{p j}\right) V_{a v}}\left[1+\frac{4 D^{\infty}}{\left(r_{p i}+r_{p j}\right) V_{a v}}\right]}
$$

Where $E(r)$ is the Van der Waals mutual attraction $(\mathrm{J}), D^{\infty}, D_{r p i r p j}$ are the particle Diffusion Coefficient $\left(\mathrm{m}^{2} \mathrm{~s}^{-1}\right)$, $V_{a v}$ is the average heat velocity of particles $\left(\mathrm{m} \mathrm{s}^{-1}\right)$. can be calculated according to equations (14)、(15)、(16)and(17)respectively. 


$$
E(r)=-\frac{A}{6}\left[\frac{2 r_{p i} r_{p j}}{r^{2}-\left(r_{p i}+r_{p j}\right)^{2}}+\frac{2 r_{p i} r_{p j}}{r^{2}-\left(r_{p i}-r_{p j}\right)^{2}}+\ln \frac{r^{2}-\left(r_{p i}+r_{p j}\right)^{2}}{r^{2}-\left(r_{p i}-r_{p j}\right)^{2}}\right]
$$

$$
D^{\infty}=D_{r_{p i}}+D_{r_{p j}}=\frac{\pi}{8} V_{r_{p i}}^{2} m_{r_{p i}} \frac{C_{c}}{6 \pi \mu r_{p i}}+\frac{\pi}{8} V_{r_{p j}}^{2} m_{r_{p j}} \frac{C_{c}}{6 \pi \mu r_{p j}}
$$

$$
\frac{D^{\infty}}{D_{r_{p i} r_{p j}}}=1+\frac{2.6 r_{p i} r_{p j}}{\left(r_{p i}+r_{p j}\right)^{2}} \sqrt{\frac{r_{p i} r_{p j}}{\left(r_{p i}+r_{p j}\right)\left(r-r_{p i}-r_{p j}\right)}}+\frac{r_{p i} r_{p j}}{\left(r_{p i}+r_{p j}\right)\left(r-r_{p i}-r_{p j}\right)}
$$

$$
V_{a v}=\left(V_{r_{p i}}^{2}+V_{r_{p j}}^{2}\right)^{1 / 2}=\left[\frac{8 k_{B} T}{\pi m_{r_{p i}}}+\frac{8 k_{B} T}{\pi m_{r_{p j}}}\right]^{1 / 2}
$$

are the mass of particles in section $i$ and $j(\mathrm{~kg})$.

From the calculation form of particle coalescence, it can be seen that Hamaker constant, particle fractal dimension and the basic sphere radius of aggregate particles are important factors that affect the change of particle coalescence. The Hamaker constant is usually determined by the particle composition and temperature; the fractal dimension of the particle and the radius of the basic sphere are closely related to the particle shape. Existing studies have shown that the composition of particles emitted by gasoline vehicles is complex, the shape is determined by the adequacy of combustion, and it is susceptible to many factors. Therefore, how to determine the values and ranges of the above three important factors affecting particle coagulation and nucleus changes through experiments and theoretical analysis will determine the accuracy of particle coagulation change prediction, which is also one of the key contents of this paper.

\section{Model Procedure}

\section{Computational Domain and Conditions.}

238 (Chen et al., 2002; Chow and Chan, 2003; Wang et al., 2019) and CFD simulation (Xue et al.,2014; Yu et al., 2014; Liu 
than its geometry and driveway model, as most vehicles are light duty vehicles with similar shape and an unidirectional lane per channel is common in urban road tunnel. direction of tunnel. The exhaust pipe in the right side of the car there is a diameter of 0.05 meters, the height of 0.3 meters outlet. STAR CCM+ was used to simulate the diffusion and coagulation of pollutants emitted by exhaust gas of a row of gasoline vehicles $(\mathrm{L} \times \mathrm{W} \times \mathrm{H}=4.5 \mathrm{~m} \times 1.8 \mathrm{~m} \times 1.5 \mathrm{~m})$ at three driving speeds. Due to the short length of the model tunnel, we assumed that the traffic wind was sufficient to eliminate pollutants. Therefore, mechanical ventilation is not used. Schematic diagrams of the tunnel geometry and vehicle model are shown in Fig. 1.

The vehicle tailpipe was defined as the velocity inlet boundary condition. Moreover, the walls surrounding the computational domain in the vertical direction were set to the flow-slip outlet condition, whereas the car surfaces were set to slip and adiabatic wall conditions. Finally, the ceiling and floor were set to no-slip and adiabatic wall conditions. In this study, the ultrafine particles discharged from the vehicles had sizes of 26-287 $\mathrm{nm}$ and when the vehicle speed is $60 \mathrm{~km} \mathrm{~h}^{-1}$, the initial concentration of particulate matter in the exhaust pipe is $17,898-172,266 \mathrm{~cm}^{-3}$; when speed is $40 \mathrm{~km} \mathrm{~h}^{-1}$, the initial particulate concentration of the exhaust pipe is $25,972-249,985 \mathrm{~cm}^{-3}$, when speed is $20 \mathrm{~km} \mathrm{~h}^{-1}$, the initial particulate concentration of the exhaust pipe is $11,007-105,941 \mathrm{~cm}^{-3}$. The exhaust velocity is $8 \mathrm{~m} \mathrm{~s}^{-1}$ and the exhaust temperature is $325 \mathrm{~K}$, the initial temperature in the tunnel was $293.15 \mathrm{~K}$. As the concentration of particles in the exhaust was at least 50 times higher than in the ambient atmosphere, the ambient particle size distribution was assumed to have minimal impact on their deposition and diffusion. Thus, the initial particle concentration for each discrete category was set to $2.72 \times 10^{3} \mathrm{~cm}^{-3}$. Owing to the complexity of the numerical simulation and the particle size distribution, we considered nine discrete categories (determined through the sectional method). All surfaces except for the vehicle tailpipes were considered to be adiabatic walls. The particle size distribution exhausted from vehicle tailpipe 
in the simulation is given in Fig 2.

Vehicle speed is one of the most important factors influencing particle dispersion and coagulation under moving conditions. Hence, in this study, we considered three different vehicle speeds, all of which were $\leq 60 \mathrm{~km} \mathrm{~h}^{-1}$, in accordance with the safety standards for tunnels in China, i.e., 20, 40, and $60 \mathrm{~km} \mathrm{~h}^{-1}$. Notably, the initial and boundary conditions were the same for all velocities.

Mesh schematic, calculation methods and model validation

Overset meshes were employed as the dynamic meshing method in this study. The calculation regions are typically divided into two parts when employing overset mesh methods, a background region and an overlapping grid region. The background region encompasses the entire computational domain and is set to be static during the numerical simulation. The overset region contains the moving body in the computational domain, which moves at a certain speed in the study. Structured hexahedron meshes were built for the background region and overset region (CD-adapco, 2013). At the border between two regions, overset mesh conditions were applied, and the meshes were refined with the same sizes to ensure the update and overlap of meshes at the overset region to the background region at each time step (CDadapco, 2013). The refined meshes between two different regions are shown in Fig. 3. 2020) are still used in the case of coagulation union. The mesh and time step independence test in Zhao et al. 2020 indicated that it is reasonable and reliable to use 0.01-s time step and 333,709-structured hexahedron mesh schemes for numerical simulation in the case of coagulation. It can not only guarantee the calculation accuracy but also improve the simulation efficiency. The model with particle dispersion and coagulation was also validated following the cases in Zhao et al., 2020. For adding coagulation, the relative error between simulation results and experimental data decreased to less than $8 \%$, compared with $10 \%$ when only considering deposition during the particle dispersion in 
All simulations were performed by solving the realizable $k-\varepsilon$ model for flow, pressure, and turbulence parameters using the CFD software STAR-CCM+. Passive scalar models with field functions were also developed in STAR-CCM+ to calculate particle dispersion and coagulation. A second-order upwind scheme and a simple algorithm were applied to all convection terms contained in the governing equations and the pressure-velocity coupling, respectively. Convergence was assumed to have been achieved at each time step when:

\section{Results and discussion}

\section{Characteristics of temperature, velocity gradient and turbulence dissipation rate}

According to the particle coagulation model, temperature, velocity gradient and turbulent dissipation rate highly dominated the particle coagulation patterns. Thus, characteristics of temperature, velocity gradient and turbulent dissipation at three representative areas including $0.1 \mathrm{~m}$ the vertical section behind the exhaust pipe of the car, the breathing area (the range 0.5-1.5 $\mathrm{m}$ high above the ground), the tunnel were analyzed and shown in Figure 4-7.

Figure 4 shows the vertical temperature nephogram of the vehicle at $60 \mathrm{~km} \mathrm{~h}^{-1}, 40 \mathrm{~km} \mathrm{~h}^{-1}$ and $20 \mathrm{~km} \mathrm{~h}^{-1}$. In order to make the consistency of vehicle locations inside the tunnel, the special time for vehicle travelling in Figure 4 was thermal plume in the vehicle wake at the back of vehicle tailpipe were observed among three different vehicle speeds. The temperature difference between the vehicle wake and the surrounding environment is about $30 \mathrm{~K}$. Moreover, the vehicle speed highly impact the thermal plume patterns, especially an inflection point at the end of the thermal plume along traffic direction. The occurrence of the thermal plume inflection is closer to the tailpipe under lower vehicle 
by the temperature difference between the vehicle exhaust and the atmospheric environment is more significant than when driving at high speed, hot vehicle exhaust plume overall rising trend. This illustrates the contradiction between the turbulence intensity and the thermal buoyancy effect, which is consistent with the results of previous studies. On the contrary, when the vehicle speed is $60 \mathrm{~km} \mathrm{~h}^{-1}$ and $40 \mathrm{~km} \mathrm{~h}^{-1}$, the fluctuation of the heat plume behind the vehicle shows a trend of first stabilizing, then rising and falling finally. The inflection point appears at $6.5 \mathrm{~m}$ and $9 \mathrm{~m}$ from the rear of the vehicle at $40 \mathrm{~km} \mathrm{~h}^{-1}$ and $60 \mathrm{~km} \mathrm{~h}^{-1}$, separately. That could be contributed to a stronger effect of the traffic wind around the car, and then a greater suppression of the turbulence induced by the traffic wind on the thermal plume of vehicle exhaust under higher vehicle speeds. The significant difference of temperature distribution, especially in the wake of vehicles might highly influence the variation of particle coagulation.

Fig. 5 shows the nephogram of the turbulent dissipation rate in the vertical direction of the trolley at speeds of 60 $\mathrm{km} \mathrm{h}^{-1}, 40 \mathrm{~km} \mathrm{~h}^{-1}$ and $20 \mathrm{~km} \mathrm{~h}^{-1}$. The length of the wake area with obvious turbulence fluctuation is about $12.5 \mathrm{~m}, 2 \mathrm{~m}$ and $0.4 \mathrm{~m}$ under $60 \mathrm{~km} \mathrm{~h}^{-1}, 40 \mathrm{~km} \mathrm{~h}^{-1}$ and $20 \mathrm{~km} \mathrm{~h}^{-1}$, respectively. The maximum value of turbulence dissipation in the wake zone with a speed of $60 \mathrm{~km} \mathrm{~h}^{-1}$ is more than $40 \mathrm{~m}^{2} \mathrm{~s}^{-3}$. The maximum value is $24 \mathrm{~m}^{2} \mathrm{~s}^{-3}$ at $40 \mathrm{~km} \mathrm{~h}^{-1}$. At $20 \mathrm{~km} \mathrm{~h}^{-}$

${ }^{1}$, the maximum value is only $2.5 \mathrm{~m}^{2} \mathrm{~s}^{-3}$. The distribution characteristics show that the turbulence dissipation rate has a great influence on the wake zone, so it must also dominate the particle coagulation characteristics of the wake zone. characteristics of turbulence dissipation rate. When the vehicle speed is $60 \mathrm{~km} \mathrm{~h}^{-1}, 40 \mathrm{~km} \mathrm{~h}^{-1}$ and $20 \mathrm{~km} \mathrm{~h}^{-1}$, the average velocity gradient in the tunnel is $1.40 \mathrm{~s}^{-1}, 1.01 \mathrm{~s}^{-1}$ and $0.61 \mathrm{~s}^{-1}$, respectively. In addition, the average velocity gradients in the breathing zone were $2.66 \mathrm{~s}^{-1}, 1.75 \mathrm{~s}^{-1}$ and $0.83 \mathrm{~s}^{-1}$, respectively. The average velocity gradients at $0.1 \mathrm{~m}$ behind the exhaust pipe are $0.89 \mathrm{~s}^{-1}, 0.69 \mathrm{~s}^{-1}$ and $0.53 \mathrm{~s}^{-1}$, respectively. 
speeds. Compared with the air velocity, when the vehicle passes through the tunnel, the overall turbulence dissipation rate increases linearly in the breathing zone and is almost constant in the tunnel. The turbulent dissipation rate at $0.1 \mathrm{~m}$ behind the exhaust pipe changes drastically at the beginning of driving, and then the value stabilizes.

When the vehicle speed is $60 \mathrm{~km} \mathrm{~h}^{-1}, 40 \mathrm{~km} \mathrm{~h}^{-1}$ and $20 \mathrm{~km} \mathrm{~h}^{-1}$, the average turbulent dissipation rate in the tunnel is $0.160 \mathrm{~m}^{2} \mathrm{~s}^{-3} 、 0.044 \mathrm{~m}^{2} \mathrm{~s}^{-3}$ and $0.005 \mathrm{~m}^{2} \mathrm{~s}^{-3}$, respectively. The average turbulent dissipation rates in the breathing zone are $0.559 \mathrm{~m}^{2} \mathrm{~s}^{-3} 、 0.133 \mathrm{~m}^{2} \mathrm{~s}^{-3}$ and $0.013 \mathrm{~m}^{2} \mathrm{~s}^{-3}$, respectively; the average turbulent dissipation rates at $0.1 \mathrm{~m}$ behind the exhaust pipe are $0.037 \mathrm{~m}^{2} \mathrm{~s}^{-3} 、 0.010 \mathrm{~m}^{2} \mathrm{~s}^{-3}$ and $0.001 \mathrm{~m}^{2} \mathrm{~s}^{-3}$, respectively. According to the results in Figure 7, it can be concluded that the turbulent dissipation rate in the breathing zone is higher than that in the whole tunnel and $0.1 \mathrm{~m}$ behind the exhaust pipe among three different vehicle speeds. This may be attributed to the enhanced vehicle exhaust and airflow dispersion in the breathing zone instead of other areas as the continue movement of vehicles inside the tunnel. The variation patterns at $0.1 \mathrm{~m}$ in the rear of the vehicle showed an increase to decrease distribution, which may be due to the high turbulence in the exhaust pipe at the beginning due to diffusion, and then gradually stabilized with the vehicle exhaust and airflow diffusion.

\section{Characteristics of particle coagulation and its impacts on particle disperison}

Fig. 8 shows the relationship between particle concentration and particle size when deposition and coagulation are both considered at the same vehicle speed and only the coagulation is considered. In order to ensure the accuracy of the conclusions, the conditions in the section $0.1 \mathrm{~m}$ behind the exhaust pipe of the vehicle, the breathing zone and the tunnel are again considered. Through comparison, it can be seen that there is no significant change in the curve considering both deposition and coagulation and considering coagulation only, and the maximum slope error is only $4.9 \%$. It can be shown that the effect of deposition on the diffusion of particulate matter is not obvious compared with coagulation, so the following data analysis of this paper directly compares the data considering coagulation only with the data and the impacts of deposition on particle dispersion were neglected. 
Figure 9 shows the relationship between particle diameter and particle concentration (calculated by arithmetic average) on a longitudinal section of $0.1 \mathrm{~m}$ from the exhaust pipe. The initial particle concentration at different speeds

349 is based on the actual emission situation (Figure 2), which is different under different vehicle speeds. From an overall observation, the changes in the concentration of particulate matter are very different from those without coagulation.

351 In the case without coagulation, particle in each size range decreased gradually during the process of vehicle movement in road tunnel. However, when considering the coagulation, particle at each size range fluctuated especially under lower $40 \mathrm{~km} \mathrm{~h}^{-1}$ and $20 \mathrm{~km} \mathrm{~h}^{-1}$. That could be attributed to complicated coagulation dynamics under the combined influence among Brownian dispersion, velocity gradient and turbulence dissipation. Unstable velocity gradient and turbulence under lower vehicle speeds could enhance the fluctuation and complexity of particle coagulation. In addition, due to the constant temperature and the same speed at the vehicle tailpipe, those unstable coagulation might be highly dominated by gradient and turbulent coagulation. In addition, the decrease patterns of particle concentration in each size range were highly influenced by particle size distribution and initial concentration. Higher concentration strengthened the particle coagulation and accelerate the decrease of particle concentration.

361 issued in our previous study for analyzing the particle deposition (Zhao et al., 2020) was again employed to evaluate.

$$
R=\frac{C_{0.5}}{C_{\text {tailpipe }}}
$$

Where $R$ describes the change of $S c$, and it can be considered that $S c$ is an indicator of the combined effect of 
corresponding particle diameters are shown in Figure 10. It could be found that for a given particle diameter range, the $R$ value obtained when considering coagulation is generally lower than that without coagulation. Meanwhile, the trends in both cases are inversely proportional to the particle size distribution. Larger error when neglecting coagulation during the particle dispersion evaluation occurred under lower vehicle speeds. The maximum relative error occurs at $91 \mathrm{~nm}$ ultrafine particle when the vehicle speed is $20 \mathrm{~km} \mathrm{~h}^{-1}$, reaching $193.51 \%$. It can be seen that the error caused by coagulation is larger and cannot be ignored. respectively under vehicle speed $60 \mathrm{~km} \mathrm{~h}^{-1}$. At the vehicle speed of $40 \mathrm{~km} \mathrm{~h}^{-1}$ and $20 \mathrm{~km} \mathrm{~h}^{-1}$, the $R$ without coagulation and with coagulation are $1.85 \% \sim 11.10 \%$ and $0.97 \sim 9.28 \%$ respectively, and the $R$ without coagulation and with coagulation are $3.02 \sim 24.80 \%$ and $1.03 \sim 9.04 \%$, separately. zone and the whole tunnel, separately. The results in Figure 11 indicated a linear increase of particle concentration during the process of vehicle movement inside the tunnel. Whereas, the tail of the trend line shows a downward trend, which was consistent to the higher diffusion effect when vehicles face to the outside of the tunnel at the exit. In addition, when the vehicle speed changes, the slope range of the curve corresponding to the breathing zone changes slightly. The slopes of the curves of the three typical particle sizes of 287, 91 and $26 \mathrm{~nm}$, without coagulation and with coagulation under vehicle speed $20 \mathrm{~km} \mathrm{~h}^{-1}$ are $-5.45 \& 0.41,60.77 \& 122,17.29 \& 42.29$ respectively. When the vehicle speed is $60 \mathrm{~km} \mathrm{~h}^{-1}$, the slope is almost unchanged being $3.49 \& 3.32,249.29 \& 247.35,87.77 \& 87.05$ respectively. and it is more obvious when driving at low speed $\left(20 \mathrm{~km} \mathrm{~h}^{-1}\right)$. Meanwhile, the slope changes from the original 60 and 
due to the presence of coagulation that causes small particles collided and coagulated into larger particles, resulting in an increase in the concentration of larger particles. When the vehicle is travelling at $60 \mathrm{~km} \mathrm{~h}^{-1}, 40 \mathrm{~km} \mathrm{~h}^{-1}$ and $20 \mathrm{~km} \mathrm{~h}^{-}$

391 , the maximum relative error of the average particle concentration in the breathing zone of the tunnel and the average particle concentration of the entire tunnel is only $0.02 \%, 2.70 \%$ and $2.82 \%$. Therefore, the effect of coagulation on particle dispersion when considering the entire tunnel could be ignored.

\section{Study limitation}

There are still several shortcomings in this study and should be conducted in the next future. Firstly, due to the lack of experiment measurement, the accuracy of the coagulation model prediction in this paper cannot be fully guaranteed. Secondly, the vehicle travelled simultaneously with the uniform speeds in this paper, the coagulation characteristics under the acceleration and deceleration conditions are not analyzed. Finally, we consider the different vehicles in a row travelled and stopped at the same vehicle speeds, which is quite different from actual random distribution of vehicle speeds even in a row. Random vehicle speeds distribution among different vehicles would be considered to evaluate the coagulation patterns more realistically.

\section{Conclusions}

This paper analyzes the unsteady temperature, velocity gradient, turbulence, vehicle exhausted ultrafine particle coagulation and diffusion characteristics when passing through a highway tunnel. The main conclusions are summarized as follows:

(1) The thermal plume rises to 6.5 and $9 \mathrm{~m}$ at $40 \mathrm{~km} \mathrm{~h}^{-1}$ and $60 \mathrm{~km} \mathrm{~h}^{-1}$ speeds, respectively, and the temperature difference between the thermal plume and the surrounding area is $30 \mathrm{~K}$. It is obvious that the velocity gradient changes with the difference of vehicle speed. When the vehicle speed is $60 \mathrm{~km} \mathrm{~h}^{-1}$, the mean value of the velocity gradient in the breathing zone is 3.2 times that of the mean value of $20 \mathrm{~km} \mathrm{~h}^{-1}$. The maximum average turbulence dissipation rate in the three different regions (the breathing zone, the tunnel and car back 
$0.1 \mathrm{~m}$ ) all appears at the speed of $40 \mathrm{~km} \mathrm{~h}^{-1}$, which is about 8.4 times of that at other speeds.

(2) Particle coagulation patterns under vehicle movements in road tunnel is quite complicated. The coagulation effect when vehicle travelled at $20 \mathrm{~km} \mathrm{~h}^{-1}$ speed is significantly stronger than that of $40 \mathrm{~km} \mathrm{~h}^{-1}$ and $60 \mathrm{~km} \mathrm{~h}^{-}$ ${ }^{1}$. If neglecting the impacts of coagulation on particle dispersion, the results will cause a large error at a vertical section of $0.1 \mathrm{~m}$ away from the exhaust pipe, as high as $193.51 \%$.

(3) The concentration of particulate matter in the breathing zone and the entire tunnel changes linearly with time. The largest difference in the slope of the particle concentration change in the tunnel occurs when the vehicle speed is $20 \mathrm{~km} / \mathrm{h}$, the relative error of $91 \mathrm{~nm}$ is only $2.82 \%$, which is less than $5 \%$, so the effect of coagulation is negligible in the entire tunnel. However, when the vehicle is travelling at low speed, it is not recommended to ignore the coagulation effect when studying the particle concentration in the breathing zone $(0.5-1.5 \mathrm{~m}$ from the ground), which is because the maximum error of the $91 \mathrm{~nm}$ particle concentration slope change can reach $59 \%$.

\section{Author's contributions}

Yu Zhao proposed the study conception of the work. Xiaocheng Song made the design of the simulation work.

Wanning Yang did the simulation and wrote the manuscript. Chaowen Jiang and Yao Feng prepared the literatures and figures. All authors read and approved the final manuscript.

\section{Funding}

This work was sponsored by the National Natural Science Foundation of China (grant number: 51808090 and $51808095)$

\section{Data availability}

All data generated or analyzed during this study are included in this paper. 


\section{Declarations}

Ethics approval and consent to participate: Not applicable.

Consent for publication: Not applicable.

Competing interests: The authors declare no conflicts of interest.

\section{References}

437 Chen, K.S., Chung, C., Wang, S.W.(2002). Measurement and three-dimensional modeling of airflow and pollutant dispersion in an undersea trafc tunnel. J. Air Waste Manage 52, 349-363. Chow, W. K. , \& Chan, M. Y. . (2003). Field measurement on transient carbon monoxide levels in vehicular tunnels. Building and Environment, 38( 2), 227-236. D. Littera,,A. Cozzolini,„M. Besch,... \& M. Gautam.(2017).Effect of turbulence intensity on PM emission of heavy duty diesel trucks - Wind tunnel studies. Atmospheric Environment(),. doi:10.1016/j.atmosenv.2017.05.013. Fuchs N A(1964). The mechanics of aerosols [M]. New York: Pergamon Press.

Gidhagen, L., Johansson, C., Str.om, J., Kristensson, A., Swietlicki, E., Pirjola, L., Hansson, H.-C., 2003. Model simulation of ultrafine particles inside a road tunnel. Atmospheric Environment 37, 2023-2036 Hinds W C(1982). Aerosol technology [M]. New York: John Wiley and Sons. Huang C M, Kerker M, Matijevic E. The effect of Brownian coagulation, gradient coagulation, turbulent coagulation, and wall losses upon the particle size distribution of an aerosol [J]. Journal of Colloid and Interface Science, 1970, 33(4): 529-538.

Kanda, I., Kiyoshi, U., Yamao, Y., Yoshikawa, Y., Morikawa, T., 2006a. A wind-tunnel study on exhaust gas dispersion from road vehicles_-Part I: velocity and concentration felds behind single vehicles. J. Wind Eng. Ind. Aerodyn. 94, 639-658 Kevin J. Lane,,Jonathan I. Levy,,Madeleine K. Scammell,... \& Doug Brugge.(2016).Association of modeled long-term personal exposure to ultrafine particles with inflammatory and coagulation biomarkers. Environment International(), doi:10.1016/j.envint.2016.03.013.

456 Kim D S, Hong S B, Kim Y J, et al. Deposition and coagulation of polydisperse nanoparticles by Brownian motion and turbulence [J]. Journal of Aerosol Science, 2006, 37(12): 1781-1787. 
Liu, Q., Nie, W., Hua, Y., Peng, H., Liu, C., Wei, C., 2019. Research on tunnel ventilation systems: dust diffusion and pollution behavior by air curtains based on CFD technology and feld measurement. Build. Environ. 147, 444-460.

461 Matthias Ketzel \& Ruwim Berkowicz.(2004).Modelling the fate of ultrafine particles from exhaust pipe to rural background: an analysis of time scales for dilution, coagulation and deposition. Atmospheric Environment(17), doi:10.1016/j.atmosenv.2004.02.020. M. Kanda,„R. Moriwaki \& F. Kasamatsu.(2006).Spatial Variability of Both Turbulent Fluxes and Temperature Profiles in an Urban Roughness Layer. Boundary-Layer Meteorology(2),. doi:10.1007/s10546-006-9063-7. M. Khairul Alam.(1987).The Effect of van der Waals and Viscous Forces on Aerosol Coagulation. Aerosol Science and Technology(1),. doi:10.1080/02786828708959118.

Okuyama K, Kousaka Y, Kida Y, et al. Turbulent coagulation of aerosols in a stirred tank [J]. Journal of Chemical Engineering of Japan, 1977, 10(2): 142-147.

Otto E, Fissan H J, Park S H, et al. The log-normal size distribution theory of Brownian aerosol coagulation for the entire particle size range: Part II: Analytical solution using the harmonic mean coagulation kernel [J]. Journal of Aerosol Science, 1999, 30(1):17-34.

Park S H, Lee K W, Otto E, et al. The log-normal size distribution theory of Brownian aerosol coagulation for the entire particle size range: Part I Analytical solution using the harmonic mean coagulation kernel [J]. Journal of Aerosol Science, 1999, 30(1):3-16. Saffman P G, Turner J S. On the collision of drops in turbulent clouds [J]. Journal of Fluid Mechanics, 1956, 1: 16-30. Shan Yin,, Junyao Lyu,, Xuyi Zhang, \& Chunjiang Liu.(2020).Coagulation effect of aero submicron particles on plant leaves: Measuring methods and potential mechanisms. Environmental Pollution(),. doi:10.1016/j.envpol.2019.113611. S.H. Park,,K.W. Lee,,M. Shimada \& K. Okuyama.(2004).Coagulation of bipolarly charged ultrafine aerosol particles. Journal of Aerosol Science(7),. doi:10.1016/j.jaerosci.2004.10.013.

481 Sturm, P.J., Baltensperger, U., Bacher, M., Lechner, B., Hausberger, S., Heiden, B., Imhof, D., Weingartner, E., Prevot, A.S.H., Kurtenbach, R., Wiesen, P., 2003. Roadside measurements of particulate matter size distribution. Atmospheric 483 Environment 37, 5273-5281.

484 Svartengren M,Strand V,,Bylin G,... \& Pershagen G.(2000).Short-term exposure to air pollution in a road tunnel 485 enhances the asthmatic response to allergen.. The European respiratory journal(4),. doi:.

486 Swift D L, Friedlander S K. The coagulation of hydrosols by Brownian motion and laminar shear flow [J]. Journal of 487 Colloid and Interface Science, 1964, 19(7): 621-647. 
488 T.L. Chan,,J.Z. Lin,,K. Zhou \& C.K. Chan.(2006).Simultaneous numerical simulation of nano and fine particle 489 coagulation and dispersion in a round jet. Journal of Aerosol Science(11),. doi:10.1016/j.jaerosci.2006.03.004.

490 Wang, M., Wang, X., Yu, L., Deng, T., 2019. Field measurements of the environmental parameter and pollutant 491 dispersion in urban undersea road tunnel. Build. Environ. 149, 100-108

492 Wright P G. On the discontinuity involved in diffusion across an interface (the delta of Fuchs) [J]. Discussions of the 493 Daraday Society, 1960, 30:100- 112..

494 Xue, P., You, S., Chao, J., Ye, T., 2014. Numerical investigation of unsteady airflow in subway influenced by piston 495 effect based on dynamic mesh. Tunn. Undergr. Space Technol. 40, 174-181

496 Yu, J., Tian, L., Zhuang, W., Yang, J., 2014. Prediction of the pollutant diffusion discharged from wind tower of the 497 city trafc tunnel. Tunn. Undergr. Space Technol. 42, 112-121.

498 Yu Zhao,,Wanning Yang,,Xiaocheng Song \& Tianyi Zhao.(2020).Deposition and dispersion characteristics of ultrafine 499 particles under different vehicle speeds in road tunnels employing dynamic mesh simulation. Environmental Science 500 and Pollution Research(prepublish),. doi:10.1007/s11356-020-09380-1.

501 Yu Zhao (2016) Research on PM1.0 dynamic and dispersion characteristics at residential underground parking lot in a 502 natural state. Harbin Institute of Technology

503 Zhu Junzong,,Qi Haiying \& Wang Jinsheng.(2013).Nanoparticle dispersion and coagulation in a turbulent round 504 jet. International Journal of Multiphase Flow(),. doi:10.1016/j.ijmultiphaseflow.2013.02.004. 
Figures

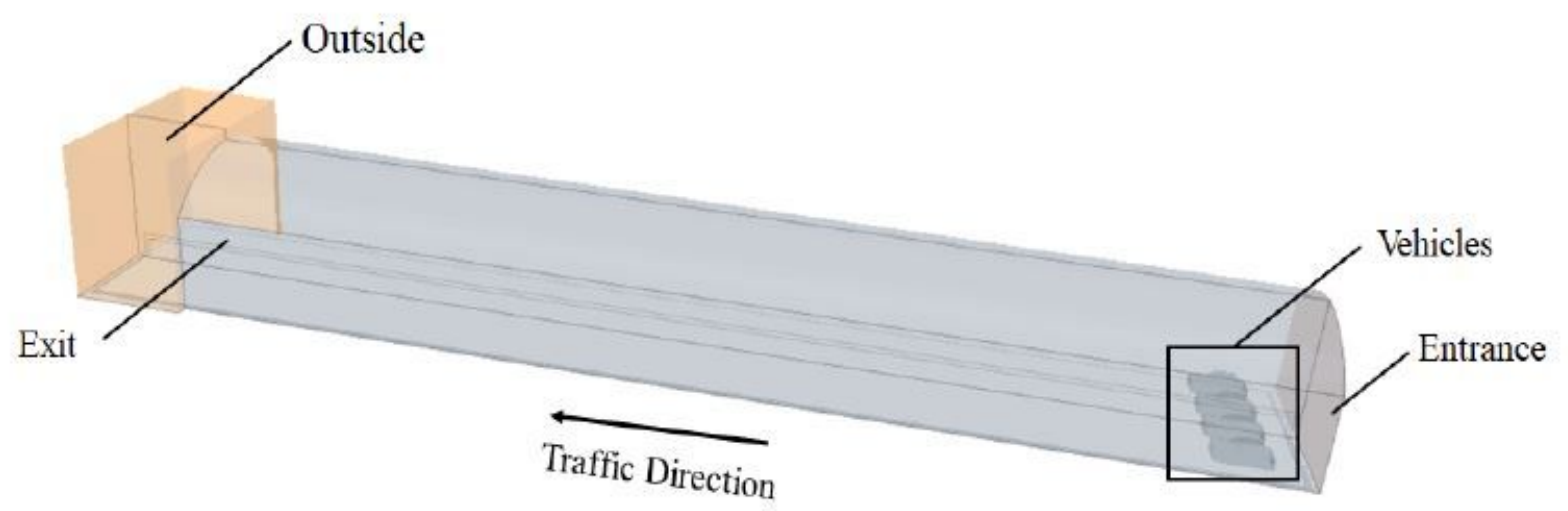

$x t^{2}$

a) Tunnel geometry

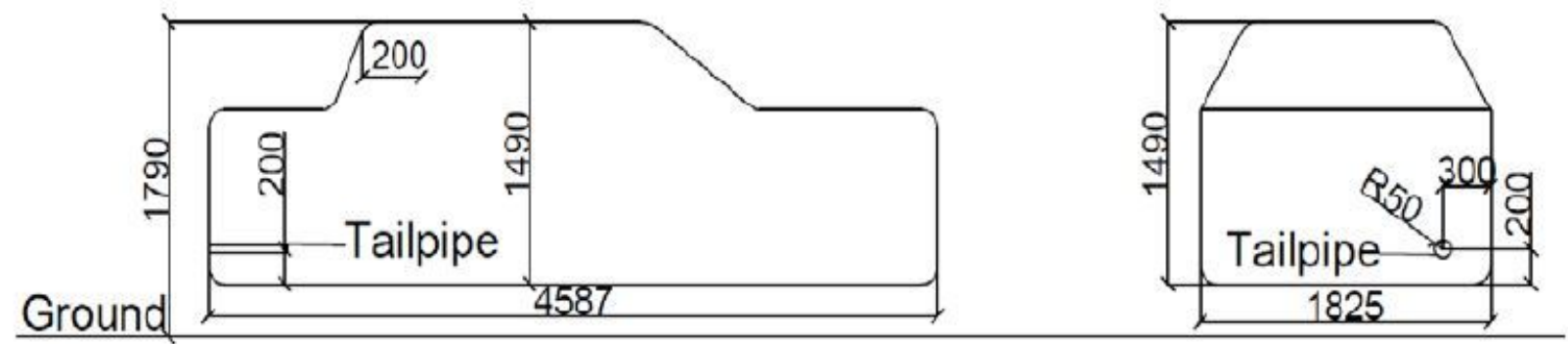

b) Vehicle model

Figure 1

Schematic diagrams showing the tunnel geometry and a vehicle model. 


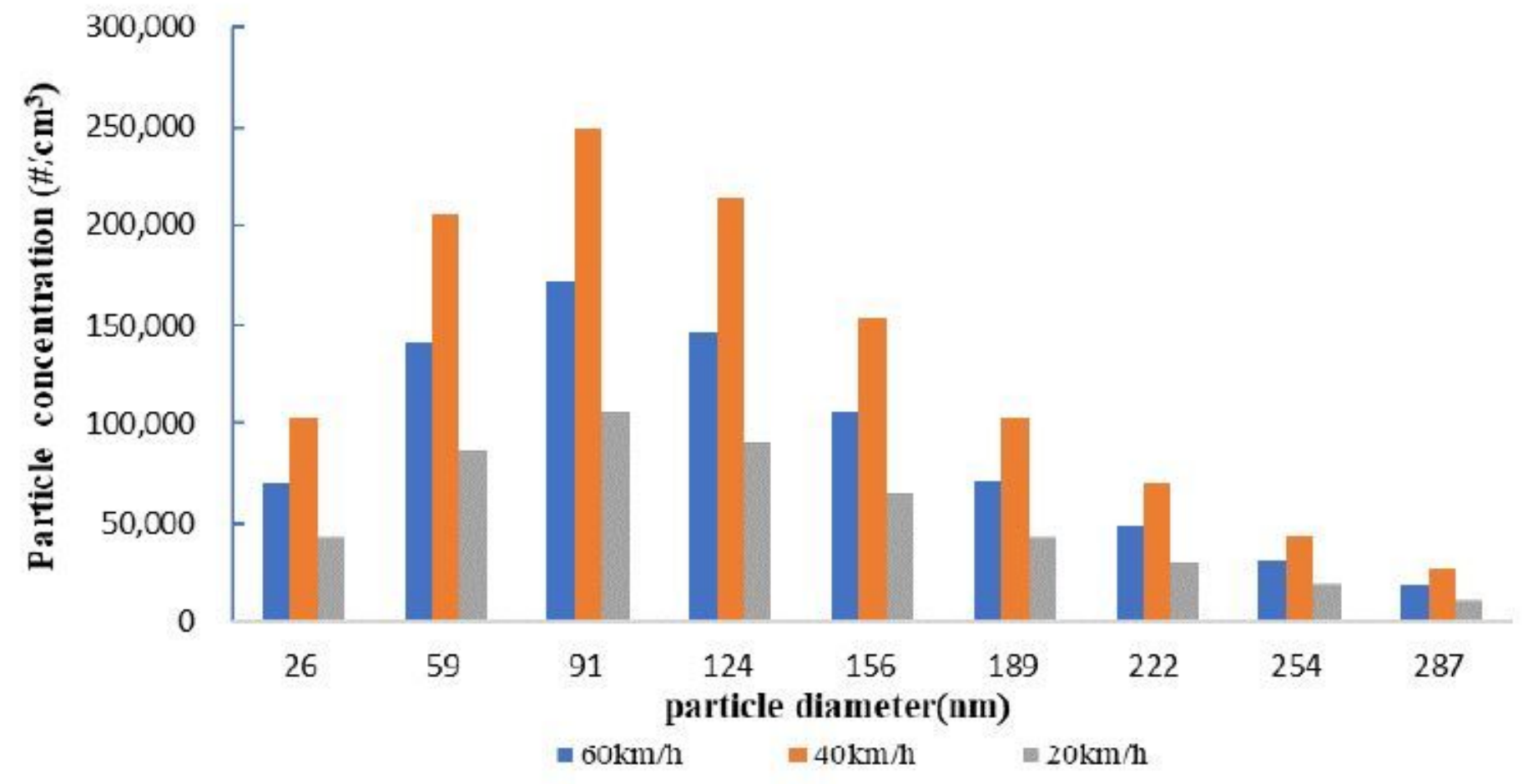

Figure 2

The relationship between the particle diameter and particle concentration in the exhaust pipe at the initial condition

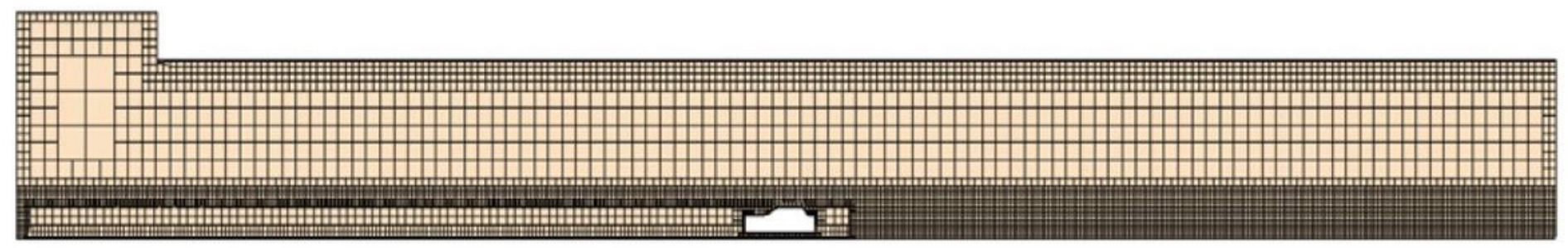

\section{Figure 3}

The refined meshes between two different regions. (When the cars running 3s) 
Temperature (K)

a) $60 \mathrm{~km} \mathrm{~h}^{-1}$ (When the cars running $3 \mathrm{~s}$ )

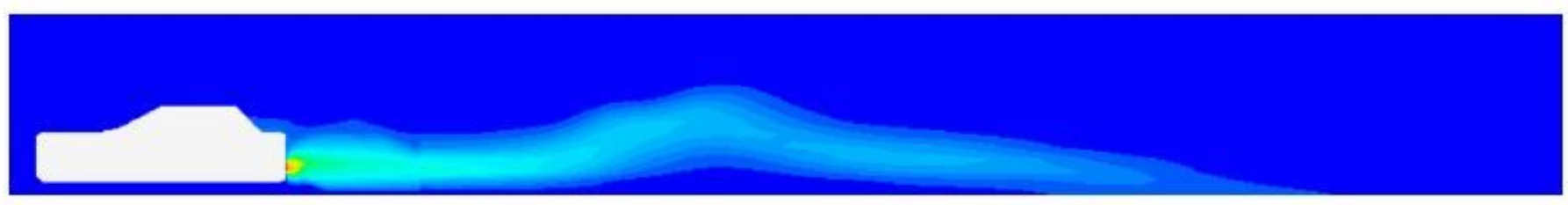

b) $40 \mathrm{~km} \mathrm{~h}^{-1}$ (When the cars running $4.5 \mathrm{~s}$ )

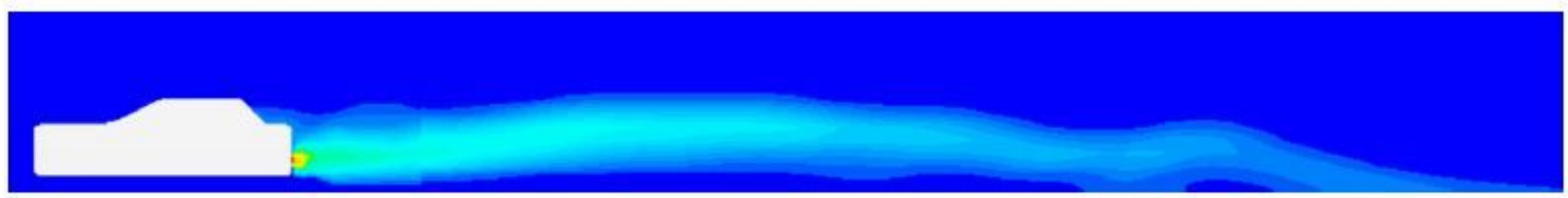

c) $20 \mathrm{~km} \mathrm{~h}^{-1}$ (When the cars running $9 \mathrm{~s}$ )

Figure 4

Temperature nephogram at the cross-section where $\mathrm{x}=2.75 \mathrm{~m}(\mathrm{~K})$ 
Turbulent Dissipation Rate $\left(\mathrm{m}^{2} / \mathrm{s}^{3}\right)$

0

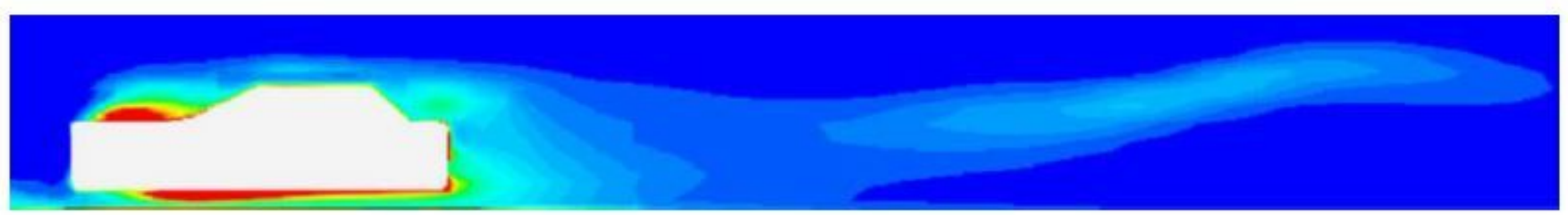

a) $60 \mathrm{~km} \mathrm{~h}^{-1}$ (When the cars running $3 \mathrm{~s}$ )

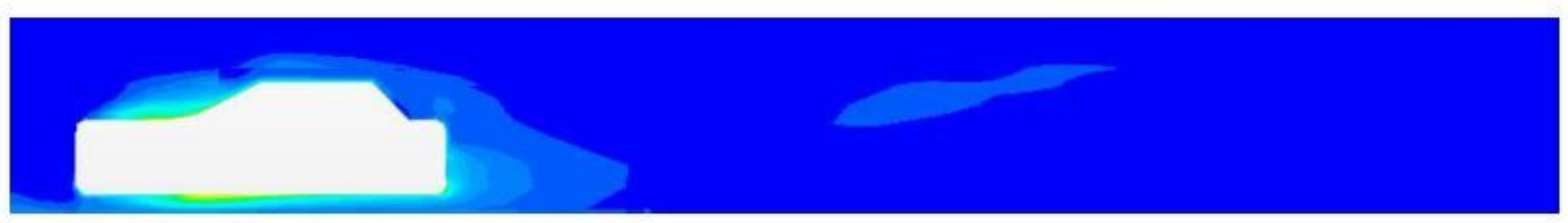

b) $40 \mathrm{~km} \mathrm{~h}^{-1}$ (When the cars running $4.5 \mathrm{~s}$ )

c) $20 \mathrm{~km} \mathrm{~h}^{-1}$ (When the cars running $9 \mathrm{~s}$ )

Figure 5

Turbulent Dissipation Rate at the cross-section where $x=2.75 \mathrm{~m}(\mathrm{~m} 2 / \mathrm{s} 3)$ 

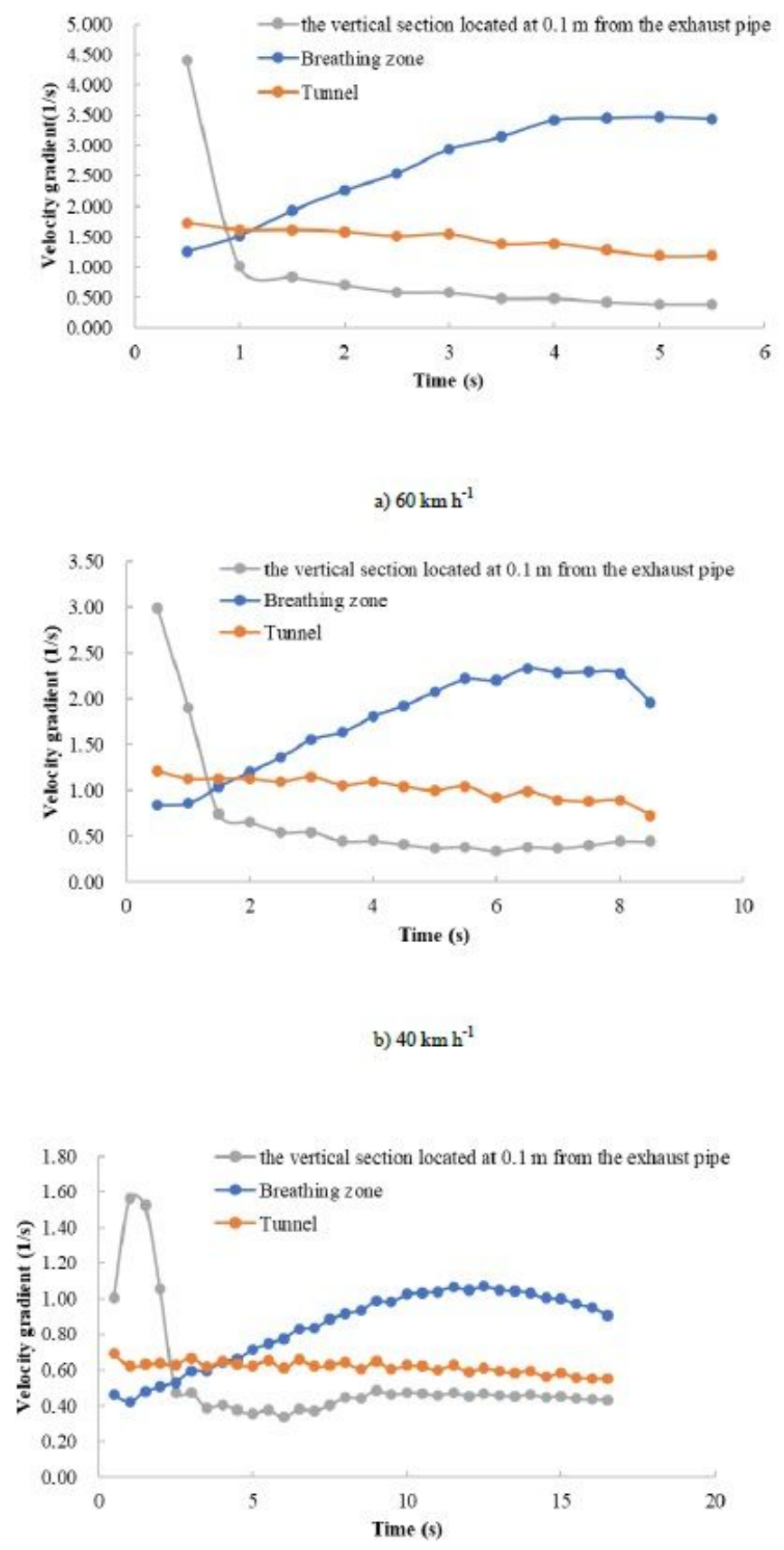

c) $20 \mathrm{~km} \mathrm{~h}^{-1}$

Figure 6

Relationship between time and the Velocity gradient (s-1) 


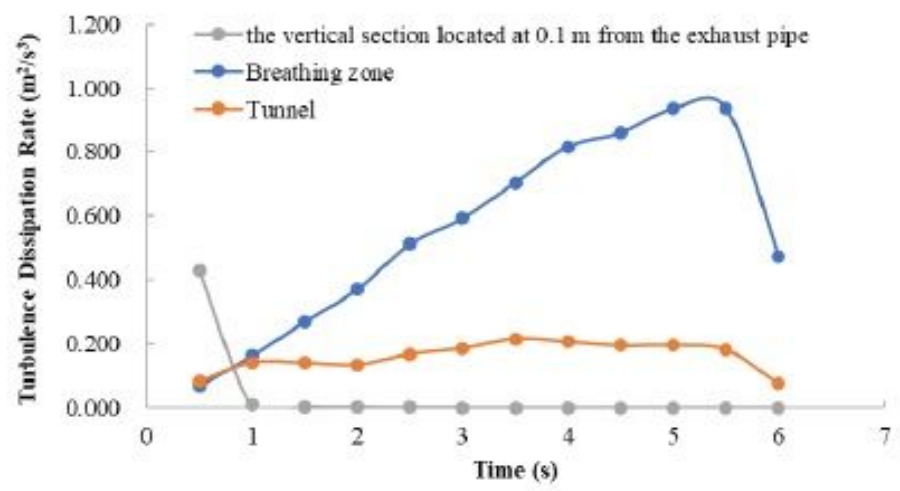

a) $60 \mathrm{~km} \mathrm{~h}^{-1}$

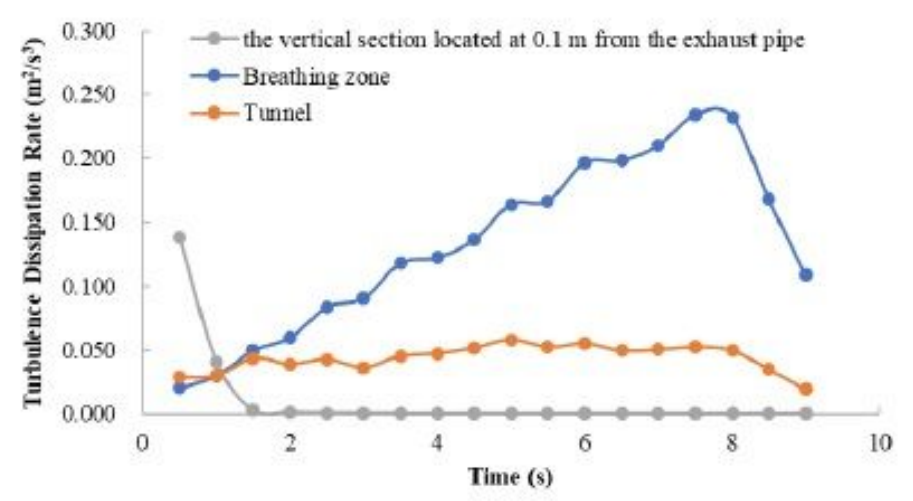

b) $40 \mathrm{~km} \mathrm{~h}^{-1}$

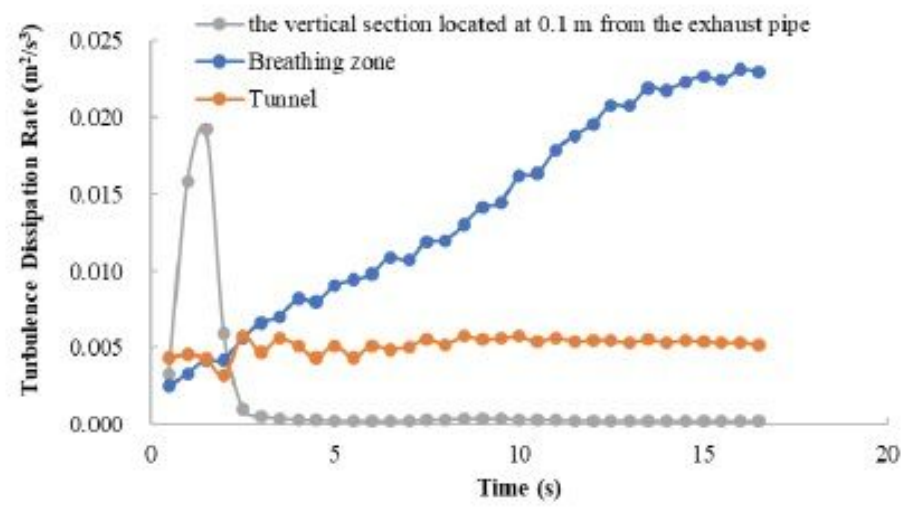

c) $20 \mathrm{~km} \mathrm{~h}^{-1}$

Figure 7

Relationship between time and the Turbulence Dissipation Rate. (m2 s-3). 


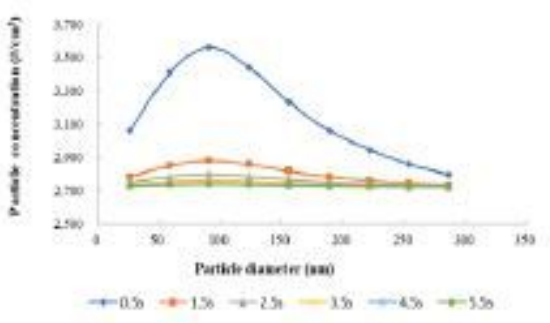

Occurrence of coagulation and deposition

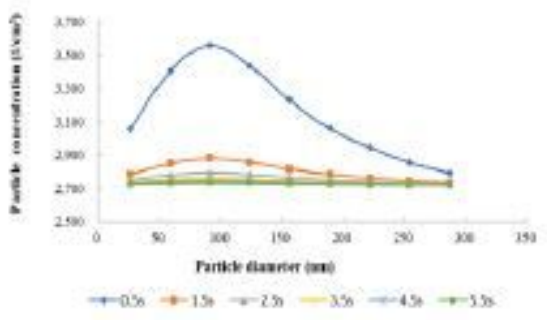

Occurrence of coagulation

a) the vertical section located at $0.1 \mathrm{~m}$ from the exhaust pipe

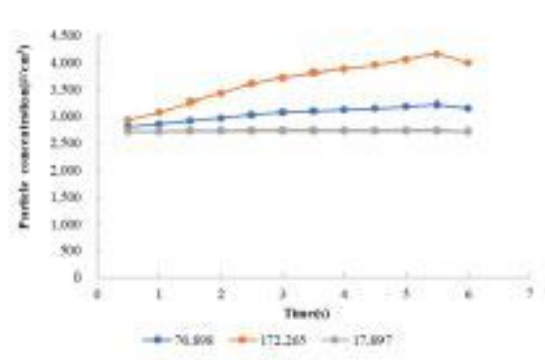

Occurrence of coagulation and deposition

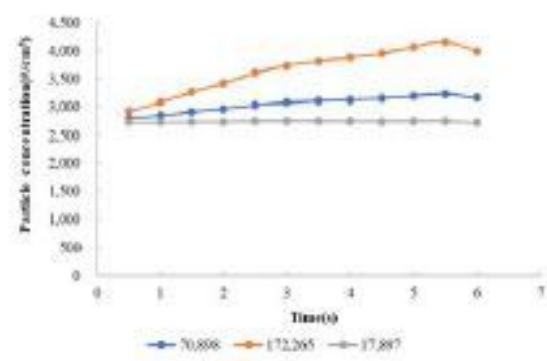

Occurrence of coagulation

b) $60 \mathrm{~km} \mathrm{~h}^{-1}$ in the breathing zone

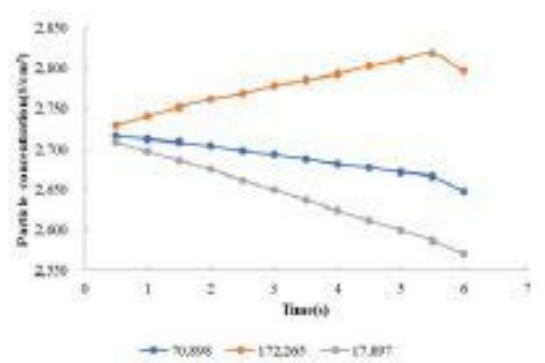

Occurrence of coagulation and deposition

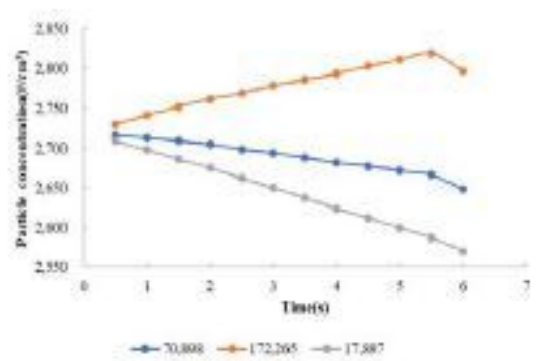

Occurrence of coagulation

c) $60 \mathrm{~km} \mathrm{~h}^{-1}$ in the tunnel

\section{Figure 8}

Relationship between particle concentration and particle size. (\# cm-3). 

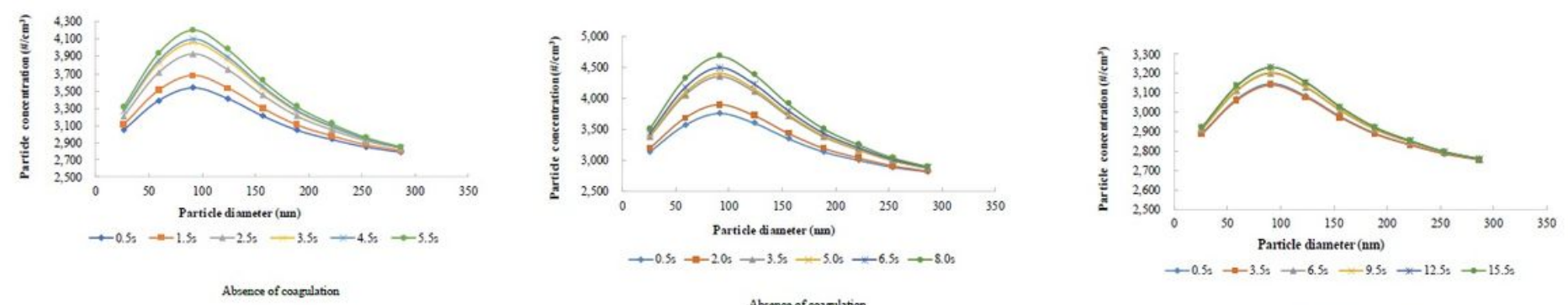

Abrence of congulation
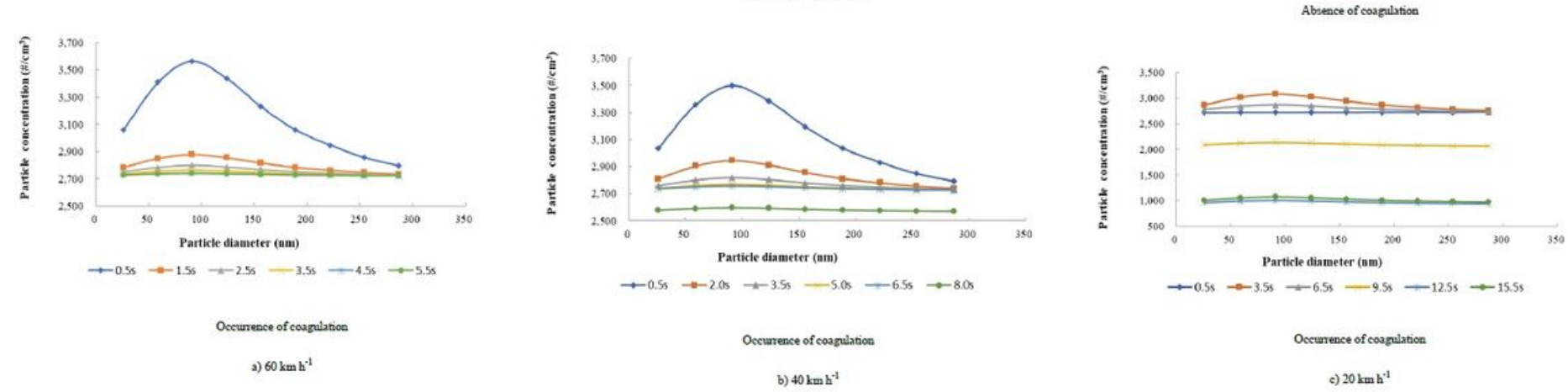

Figure 9

Relationship between the particle diameter and the averaged particle size distribution in correspondence of the vertical section located at $0.1 \mathrm{~m}$ from the exhaust pipe. 


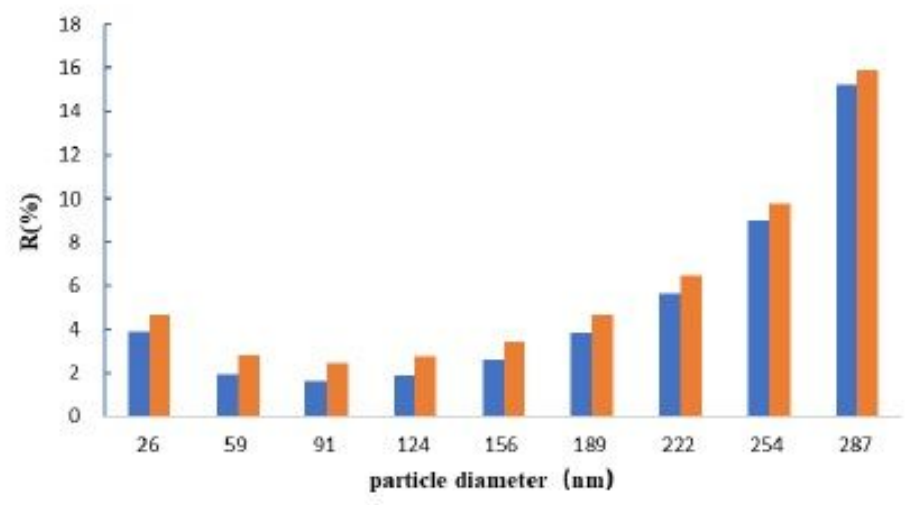

with coagulate $\mid$ without coagulate

a) $60 \mathrm{~km} \mathrm{~h}^{-1}$
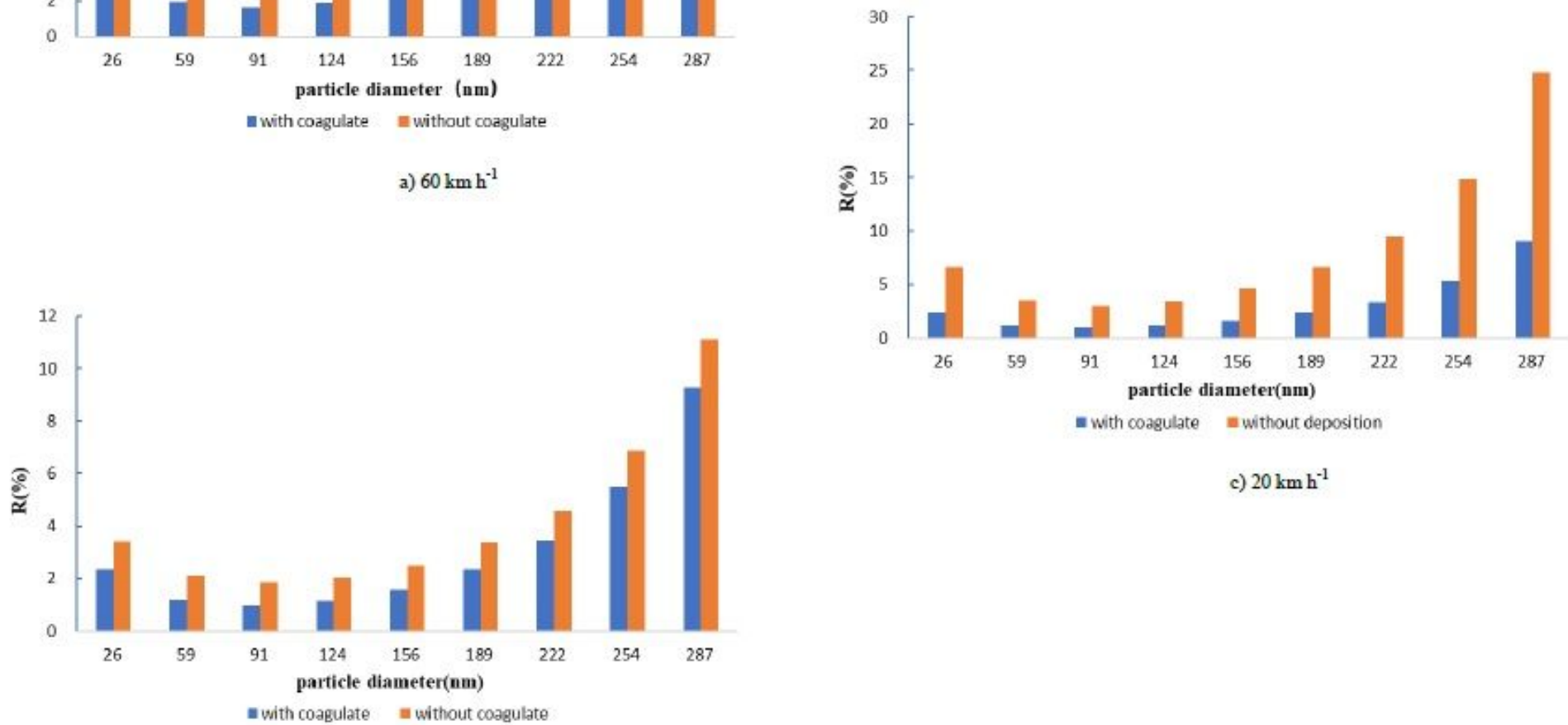

c) $20 \mathrm{~km} \mathrm{~h}^{-1}$

b) $40 \mathrm{~km} \mathrm{~h}^{-1}$

\section{Figure 10}

Relationship between the particle diameters and the $\mathrm{R}$ values in correspondence of the vertical section located at $0.1 \mathrm{~m}$ from the tailpipe. 

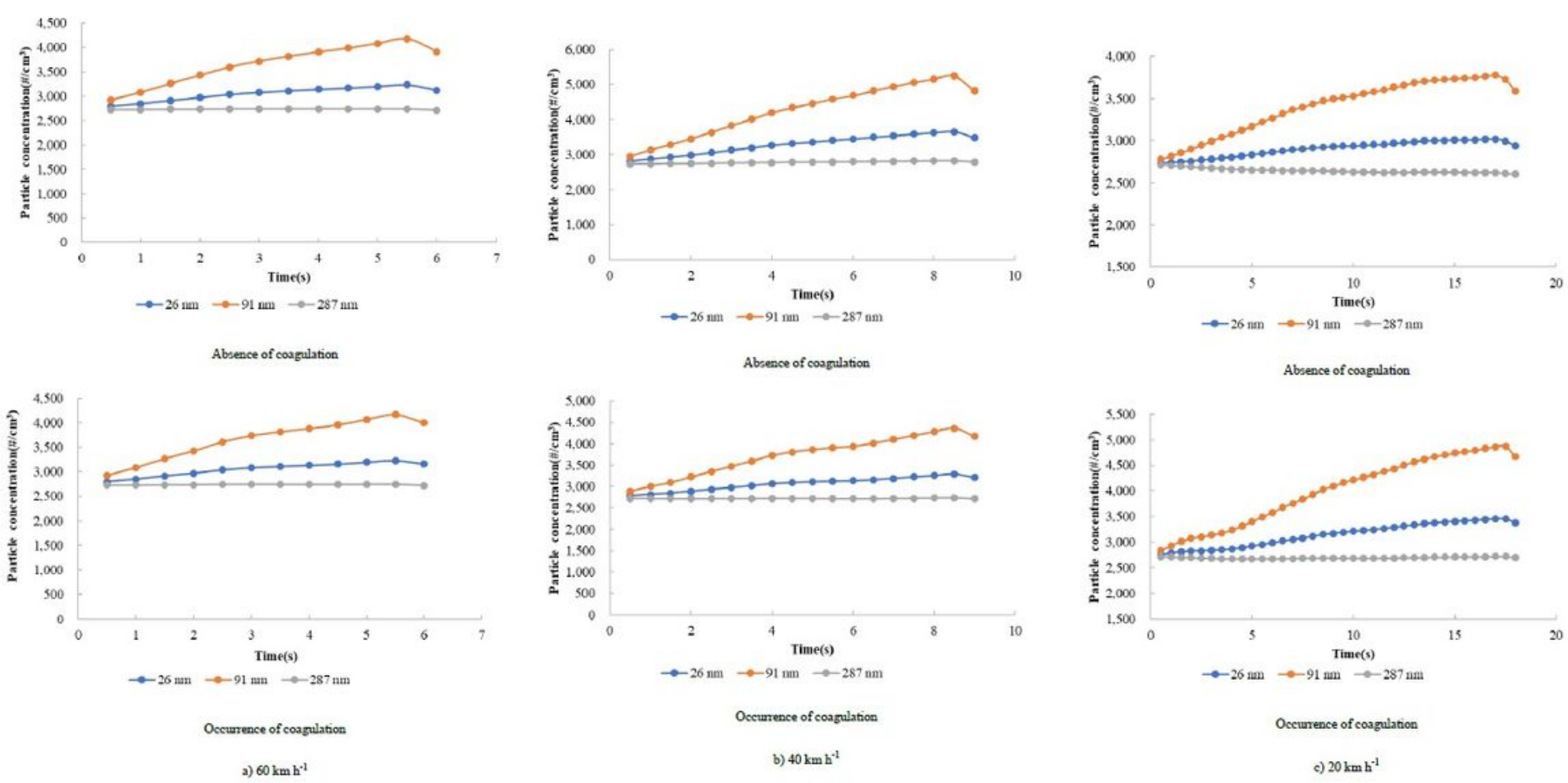

\section{Figure 11}

Relationship between time and the averaged particle concentration in the breathing zone. The numbers in the legends indicate different initial particle concentration (\# cm-3).
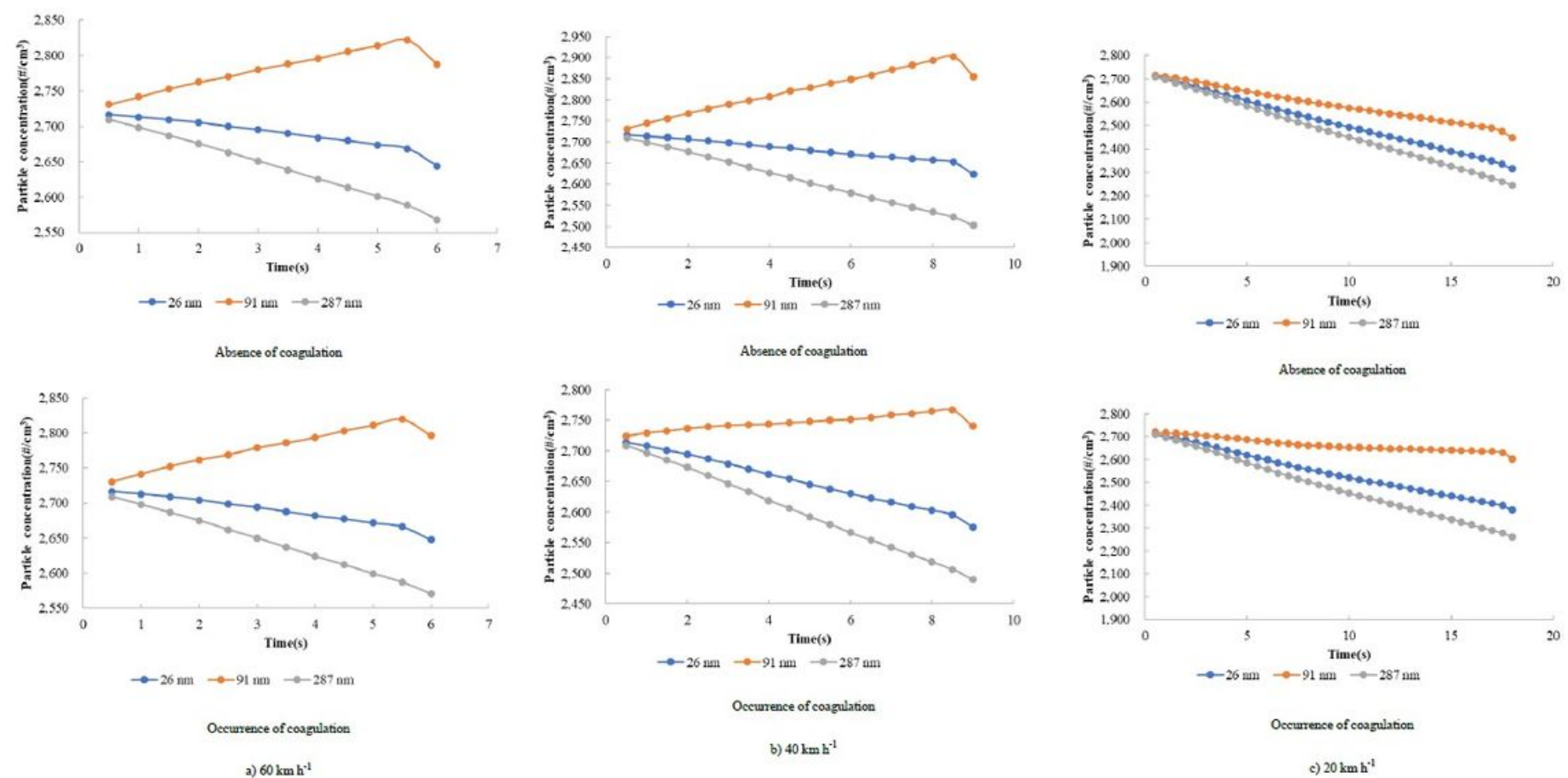

Figure 12 
Relationship between time and the averaged particle concentration in the tunnel. The numbers in the legends indicate different initial particle concentration (\# cm-3). 